\title{
Hospital Epidemiology: Issues in Quality of Care
}

When it first became available, zidovudine was referred to as AZT. Although additional agents are now available, zidovudine (Retrovir) remains a mainstay of antiretroviral therapy. After the second episode of incorrect dispensing of azathioprine (Imuran) instead of zidovudine (Retrovir), one major teaching hospital instituted a policy of mandating a phone call to any physician who persisted in ordering zidovudine (or azathi- oprine) as $\mathrm{AZT}$, to clarify the order. These errors of dispensing, despite published reports, ${ }^{1}$ illustrate the need for each hospital to use its own data to improve processes that affect the quality of care, as opposed to relying on published reports to bring such problems to the attention of medical staff.

The editors of this news page would like to know whether any of our members have encountered the situation where physician prescription of zidovudine by usage of the three letters AZT has led to the mistaken dispensing of azathioprine. Please let us know of your knowledge of any such mishaps, and the improvements that were used to prevent recurrences.

\section{REFERENCES}

1. Landis SJ. Azathioprine or azidothymidine? Can Med Assoc J. 1990;143:611.

\section{Pa pers from Infection Control and Hospital Epidemiology to be Reprinted in a new Italian Journal}

View and Review, the first periodical in Italy on hospital infections and sanitation, has approached SHEA for permission to reprint up to six articles per year from Infection Control and Hospital Epidemiology. The SHEA Board approved this arrangement with the Italian journal at its recent meeting in January 1993. In addition, View and Review will be publishing a subscription advertisement for Infection Control and Hospital Epidemiology.
The Society is pleased to share these scientific papers with our Italian colleagues, and we hope they find them useful in their practice of hospital epidemiology and infection control.

\section{Changes in the 1993 SHEA/CDC/AHA Training Course}

For 1993, the ever-popular SHEA/CDC/American Hospital Association (AHA) Training Course in Hospital Epidemiology will be offered only once.

According to Dr. Donald Goldmann, course director, "We should be able to accommodate all who are interested in attending and still be able to maintain the high quality of teaching and audience-staff interaction." In addition, Talley Management Group will take over management of the course from the AHA. The

Brief items of interest for the SHEA News or Newsletter may be sent to C. Glen Mayhall, MD, SHEA, N ew sletter Editor, Division of Infectious Diseases, Department of Medicine, University of Tennessee, Memphis, 956 Court Ave., Memphis, TN 38163; FAX (901) 528-5854. Copy should be typed, double-spaced, and should not exceed five pages. 